\title{
Evaluation of the 5-HTTLPR and 5-HTTVNTR Polymorphisms in the Serotonin Transporter Gene in Women with Postpartum Depression
}

\author{
Josi Maria Zimmermann-Peruzatto ${ }^{1}$, Silvana Almeida ${ }^{2}$, Aldo Bolten Lucion ${ }^{1}$, Jean Pierre Oses ${ }^{3}$, \\ Luciana Ávila Quevedo ${ }^{3}$, Karen Amaral Tavares Pinheiro ${ }^{3}$, Ricardo Azevedo da Silva ${ }^{3}$, \\ Ricardo Tavares Pinheiro ${ }^{3}$, Márcia Giovenardi ${ }^{1,2}$
}

${ }^{1}$ Programa de Pós-Graduação em Ciências Biológicas, Fisiologia, Universidade Federal do Rio Grande do Sul, Porto Alegre, Brazil; ${ }^{2}$ Programa de Pós-Graduação em Ciências da Saúde, Universidade Federal de Ciências da Saúde de Porto Alegre, Porto Alegre, Brazil; ${ }^{3}$ Programa de Pós-Graduação em Saúde \& Comportamento, Centro de Ciências da Vida e da Saúde, Universidade Católica de Pelotas, Pelotas, Brazil.

Email: mgiovenardi@yahoo.com.br

Received May $16^{\text {th }}, 2012$; revised June $25^{\text {th }}, 2012$; accepted July $3^{\text {rd }}, 2012$

\begin{abstract}
Objective: The purpose of the present study was to evaluate the association between the 5-HTTLPR and 5-HTTVNTR polymorphisms in the serotonin transporter gene (SLC6A4) in Brazilian women with diagnosed postpartum depression (PPD) and the presence of depressive symptoms. Method: The cohort consisted of 128 white women who were characterized based on skin color and morphological characteristics. The Beck Depression Inventory was used to diagnose PPD and to score the depressive symptoms. The 5-HTTLPR and 5-HTTVNTR polymorphisms were analyzed by PCR-based methods. Results: No association was observed between the PPD diagnosis and either the 5-HTTLPR $(\mathrm{p}=$ $0.48)$ or the $5-H T T V N T R(p=0.77)$ polymorphism. When the polymorphisms were analyzed together with haplotype data, the analyses demonstrated that women carriers of the L-12/L-12 diplotype have lower Beck Depression Inventory scores than women carrying other diplotypes $(\mathrm{p}=0.04)$. Discussion: Few studies have investigated the association of SLC6A4 polymorphisms with PPD, and the role of 5-HTTLPR and 5-HTTVNTR polymorphisms in PPD susceptibility has not been established to date. Therefore, our findings link the haplotypes of these two variants with depression symptoms, thereby contributing to our understanding of PPD susceptibility.
\end{abstract}

Keywords: Postpartum Depression; Serotonin Transporter; 5-HTTLPR; 5-HTTVNTR; Polymorphisms

\section{Introduction}

Postpartum depression (PPD) is mood disorder; it is similar to major depressive disorder but usually presents within the first 4 to 6 weeks after delivery [1]. A metaanalysis has estimated that PPD is prevalent worldwide and affects $10 \%$ to $15 \%$ of women [2]. In the Brazilian population, the incidence of maternal depression in the samples studied ranged from $7.2 \%$ [3] to $26.9 \%$ [4]. PPD differs from the "baby blues" because in most cases it affects the functionality of the mother and endangers the well-being of both the mother and the baby. PPD can be a devastating disease for the mother, can harm the neurocognitive and socio-emotional development of the child, and can increase the risk for mental and medical disorders in the child later in life [5]. PPD is a multifactorial disease; PPD susceptibility is related to psychological, biological (including hormonal changes and genetic vulnerability), and social factors [6]. The risk of occurrence is higher in women with a history of major depression [7], previous PPD [8], or a family history of depression [9]. Therefore, according to Forty et al. [9], there is a genetic component for the development of this disorder.

According to the DSM-IV (Diagnostic and Statistical Manual of Mental Disorder, Fourth Edition) [1], there is a relationship between depressive symptoms and changes in the concentration of neurotransmitters, especially serotonin (5-HT), in the brain. Decreased levels of 5-HT are among the factors contributing to the etiology of major depression [10]. The serotonin transporter (SERT) is located in the presynaptic membrane of serotonergic neurons, where it controls the intensity and duration of serotonergic signaling through the re-uptake of 5-HT in the synaptic cleft [11].

SERT is encoded by the SLC6A4 gene located within the 17q11.1-q12 region [12] of chromosome 17 . The 
expression of this gene is influenced by its genetic variants. Two polymorphisms have been widely studied. The 5-HTTLPR polymorphism (resulting from an insertion/ deletion) is located in the promoter region [13] and has a long allele (L: with an insertion of $44 \mathrm{bp}$ ) and short allele (S). The 5-HTTVNTR polymorphism (containing a variable number of tandem repeats) is in the second intron and has a repetition unit containing $17 \mathrm{bp}$. Three alleles of 5-HTTVNTR have been described and contain 9, 10, or 12 repetitions [14].

SLC6A4 has been identified as a candidate gene for mood disorders because several studies have associated SLC6A4 polymorphisms with the development of major depression [15-18] and bipolar disorder [19]. To the best of our knowledge, only two previous studies have investtigated the association between SLC6A4 polymorphisms and depression scores in postpartum women [20,21]. The results from the previous studies contradicted other studies that evaluated SLC6A4 polymorphisms for association with mood disorders in other life periods [15-23]. Our present study aimed to determine the association between the 5-HTTLPR and 5-HTTVNTR polymorphisms and both PPD diagnosis and the Beck Depressive Inventory (BDI) score (a measure of depressive symptoms) in a group of Brazilian women. These results may impact the treatment of PPD.

\section{Materials and Methods}

\subsection{Subjects}

A cohort study consisting for pregnant women who were recruited from the Brazilian National System of Public Heath from 2006 to 2008 was utilized. All women seeking prenatal care in the public health system of Pelotas City were visited and were invited to participate in the study. All participants were all at least 18 years of age, lived in the urban area, and were capable of understanding and answering the sociodemographic questionnaire included in the study. In the study, 128 white women were included; this classification was based in skin color and morphological characteristics as described by Parra et al. [24]. This study was approved by the Ethics Committee of the Universidade Federal de Ciências da Saúde de Porto Alegre (n.270/07) and National Council on Ethics in Research (n.44/08). All subjects signed an informed consent form.

\subsection{Depressive Symptoms Access}

The mothers were visited at home and were interviewed; they also provided blood samples for genetic analyses within 45 to 90 days of delivery. The validated Portuguese version of the BDI [25] was employed to detect depressive symptomatology in the mother. BDI results were used for diagnosis of PPD. A cutoff score of 18 was used to differentiate between mild and moderate/severe depression.

\subsection{DNA Analyses}

The blood used for DNA extraction was collected by a trained professional in the residence of each participant. Genomic DNA was extracted from peripheral blood leukocytes by a salting-out procedure [26]. DNA fragments with the 5-HTTVNTR polymorphism were amplified by polymerase chain reaction (PCR) using the forward primer 5' GTCAGTATCACAGGCTGCGAG 3' and the reverse primer 5' TGTTCCTAGTCTTACGCCAGTG 3' and employing conditions that were previously described [27]. The amplification of the 5-HTTLPR polymorphism was performed using the forward primer

5' GCGCTCCTGCATCCCCCATTA 3' and the reverse primer 5' GGGATGCGGGGGAATACTGGT 3'; this PCR reaction produced a $297 \mathrm{bp}$ (L allele) and a $253 \mathrm{bp}$ (S allele) fragment [12]. The genotypes of 5-HTTLPR and 5-HTTVNTR were determined by separating the amplified products by electrophoresis on a $2.5 \%$ agarose gel containing ethidium bromide and using a 50-bp ladder to determine band sizes.

\subsection{Statistical Analysis}

Allele frequencies were estimated by gene counting. A $\chi^{2}$ test for goodness of fit was used to determine whether the observed allele frequencies agreed with those expected under Hardy-Weinberg equilibrium. Haplotype frequencies and linkage disequilibrium were estimated using the Multiple Locus Haplotype Analysis program version $2.0[28,29]$ and Arlequin software version 3.1 [30]. A $\chi^{2}$ test with Yates correction was used to compare allele and genotype frequencies of the 5-HTTLPR and 5-HTTVNTR polymorphisms for individuals with a PPD diagnosis (BDI $\geq 18$ ) and for individuals without a PPD diagnosis (BDI < 18). Because of the low frequency of the $9 / 12$ genotype $(5-H T T V N T R)$ in this cohort $(n=1)$, this woman was excluded from statistical analyses invest- tigating the association of this polymorphism with PPD diagnosis. The BDI scores were compared among carriers of different diplotypes; Mann-Whitney tests were used, and a 5\% significance level was chosen. The Benjamini and Hochberg [31] false discovery rate procedure was performed to correct for multiple testing, and corrected $\mathrm{P}$ values were reported.

\section{Results}

The genotype frequency distributions of the 5-HTTLPR and 5-HTTVNTR polymorphisms were in agreement with Hardy-Weinberg expectations. The genotype frequencies 
for the 5-HTTLPR polymorphism were $17.0 \%(\mathrm{n}=22)$ for $S / S, 51.0 \%(n=65)$ for $L / S$, and $32.0 \%(n=41)$ for $\mathrm{L} / \mathrm{L}$. The genotype frequencies for the 5-HTTVNTR polymorphism were $0.70 \%(n=1)$ for $9 / 12,14.70 \%(n=17)$ for $10 / 10,44.0 \%(n=51)$ for $10 / 12$, and $40.60 \%(n=48)$ for $12 / 12$. Eleven women were not genotyped for the 5-HTVNTR polymorphism due to technical difficulties; therefore, the analyzed sample set included 117 individuals for this polymorphism. Linkage disequilibrium was detected between the two polymorphisms (the D' value was $0.61, p=0.003$ ). All four possible haplotypes were found in this cohort; the more common haplotypes were S-12 (frequency of $36.24 \%$; $n=42)$, L-10 (29.71\%; $n=35)$, L-12 (27.17\%; $n=32)$, and S-10 (6.88\%; $n=8)$.

Results from the association analyses between the 5-HTTLPR and 5-HTTVNTR polymorphisms and PPD diagnosis (according to the BDI) in women are presented in Table 1. When the polymorphisms were analyzed alone, no association was observed between the 5HTTLPR $(\mathrm{p}=0.48)$ and 5-HTTVNTR $(\mathrm{p}=0.77)$ polymorphisms and PPD diagnosis. Utilizing haplotype information for the 5-HTTLPR and 5-HTTVNTR polymorphisms demonstrated that women carriers of the L-12/L-12 diplotype have a lower BDI score (median: 0.5 ; inter-quartile range: $0.00-4.00 ; \mathrm{p}=0.04$; corrected $\mathrm{p}=0.12$ ) than women with other diplotypes (median: 4.0; inter-quartile range: $1.00-10.00)$. These results are shown in Figure 1.

\section{Discussion}

The present study analyzed the PPD diagnoses of women, which were made between 45 and 90 days after delivery. No association between SLC6A4 gene polymorphisms and PPD was found when PPD was analyzed alone. However, the results indicated that specific haplotypes of the 5-HTTVNTR and 5-HTTLPR polymorphisms were associated with depression score.

The relationship between the 5-HTTLPR and 5-

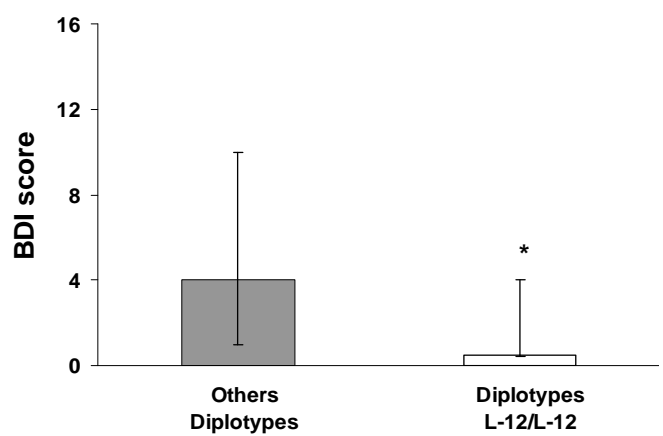

Figure 1. Beck Depression Inventory (BDI) score according to the 5-HTTLPR and 5-HTTVNTR polymorphisms diplotypes.
HTTVNTR polymorphisms and SERT function and expression is not yet fully understood, although several previous reports have investigated the relationship. Heils et al. [32] performed an in vitro functional study and demonstrated that the promoter region initiated transcription of the 5-HTTLPR*L allele more efficiently than it promoted transcription of the $\mathrm{S}$ allele. Therefore, individuals with the $\mathrm{L} / \mathrm{L}$ genotype expressed more SERT than those with $\mathrm{S} / \mathrm{L}$ and $\mathrm{S} / \mathrm{S}$ genotypes. Other studies also found an association between the 5-HTTLPR*S allele $[16,17,33,34]$ and the 10 and 12 alleles of the 5-HTTVNTR polymorphism [19,23]; women with these alleles exhibited lower SERT transcription efficiency. Functional magnetic resonance imaging analyses have revealed that carriers of the $\mathrm{S}$ allele have reduced volumes of the perigenual anterior cingulate cortex and amygdala [33]. Although these studies have provided information related to the relationship between these polymorphisms and the risk of developing mental disorders, such as depression, more information is required to fully understand this functional relationship.

Several studies have investigated the association of the 5-HTTLPR polymorphism with mood disorders. According to Pascual et al. [23], the presence of the $S$ allele was significantly associated with the development of a mental disorder. Caspi et al. [15] determined that individuals carrying the $\mathrm{S}$ allele had more depressive symptoms, were more frequently diagnosed with depression, and had more suicidal thoughts during stressful life events compared to individuals who were homozygous for the $\mathrm{L}$ allele. Xie et al. [6] found that individuals with one or two copies of the $\mathrm{S}$ allele have an increased risk of developing posttraumatic stress disorder following exposure to adverse environmental events. Moreover, Zalsman et al. [17] demonstrated that individuals who carry the $S$ allele are more reactive to unfavorable environmental events often associated with major depression. Wilhelm et al. [16] and Taylor et al. [22] observed that individuals homozygous for the $\mathrm{S}$ allele showed greater depressive symptomatology when exposed to stress compared with those harboring the S/L or L/L genotype. Taken together, these studies indicate that the 5-HTTLPR genotype does not determine the development of the disorder per se. However, when exposed to stressful events, individuals with one or two copies of the $\mathrm{S}$ allele are more likely than L/L homozygotes to develop the disorder. Conversely, the results of Chorbov et al. [35] and Laucht et al. [36] suggest a different conclusion from the one described above. These studies found that individuals with the L/L genotype who were exposed to adverse environmental events exhibited an increased risk of depression.

Specific to PPD, our results showed no association between the 5-HTTLPR genotype alone and PPD in white women (Table 1). This conclusion agreed with 
Table 1. 5-HTTLPR and 5-HTTVNTR genotype frequencies in women with diagnosed postpartum depression according to the Beck Depression Inventory (BDI) classification. The number of women (n) is given between parentheses.

\begin{tabular}{ccccc}
\hline \multicolumn{5}{c}{ 5-HTTLPR } \\
\hline Genotypes & S/S & L/S & L/L & $\mathrm{p}$ \\
NON-PPD & $16.90 \%(19)$ & $50.40 \%(57)$ & $32.70 \%(37)$ & 0.48 \\
PPD & $13.30 \%(2)$ & $66.70 \%(10)$ & $20.00 \%(3)$ & \\
\hline \multicolumn{5}{c}{$5-H T T V N T R$} \\
Genotypes & $10 / 10$ & $10 / 12$ & $12 / 12$ & $\mathrm{p}$ \\
NON-PPD & $15.10 \%(16)$ & $41.50 \%(44)$ & $43.40 \%(46)$ & 0.77 \\
PPD & $9.00 \%(1)$ & $45.50 \%(5)$ & $45.50 \%(5)$ \\
\hline
\end{tabular}

several studies that found no significant relationship between the 5-HTTLPR polymorphism and the development of mood disorders, such as major depression [37], depression and attempted suicide [38], depression and stressful life events [39], and bipolar disorders [40]. In a meta-analysis, Risch et al. [18] observed no association between the 5-HTTLPR genotype, either alone or in conjunction with stressful events, and risk for depression in either gender.

Our results showed no an association between the 5-HTTVNTR polymorphisms and PPD in white women. Additionally, Alaerts et al. [40] did not find an association between the 5-HTTVNTR polymorphisms and bipolar disorder, and Assal et al. [41] found no relationship between the 5-HTTVNTR polymorphisms and agitation/ aggression, depression, or anxiety. However, in a previous study, the increased frequency of the 5-HTTVNTR*12 allele was observed in subjects with bipolar disorder but not in subjects diagnosed with major depression [19]. Kumar et al. [42] observed an association between the 5 -HTTVNTR*10 allele and puerperal psychosis.

To the best of our knowledge, only two previous studies have investigated the relationship between serotoninrelated polymorphisms and PPD. Sanjuan et al. [20] reported that at 8 weeks postpartum, high expression of specific SERT genotypes (L/L of 5-HTTLPR and 12/12 of 5-HTTVNTR polymorphisms) was associated with an increase in the Edinburgh Postnatal Depression Scale (EPDS) score. Doornbos et al. [21] indicated that female 5-HTTLPR*L carriers trended toward increased depresssion scores at 6 weeks postpartum. In our study, no significant associations between the SLC6A4 gene polymorphism and PPD diagnosis were detected when the analyses were performed separately for each polymerphism (Table 1). When the two genetic variants were analyzed together with their haplotypes, women carrying the L-12/L-12 diplotype exhibited a lower BDI score compared to women carrying other diplotypes (Figure 1). This conclusion is different than that reported by Sanjuan et al. [20]. However, these two studies are not entirely comparable because different scales were used for PPD diagnosis, and the postpartum period for each study was different. Additionally, our findings are partially corroborated by several studies that found an association between the presence of the $5-H T T L P R * S[6,15-17,22]$ and 5-HTTVNTR*10 alleles [42] with mood disorders; in our study, the L-12/L-12 diplotype was associated with a lower BDI score, indicating that this diplotype could partially protect an individual from developing PPD.

Our findings are important because few studies have investigated the association of specific haplotypes of the 5-HTTLPR and 5-HTTVNTR polymorphisms with PPD. In summary, we present evidence that postpartum women carrying the L-12/L-12 diplotype exhibit fewer depression symptoms than those carrying other diplotypes. Moreover, this result implicates genetic variations in the SERT gene as playing a role in the etiology of PPD. An inherent limitation to our study is the small sample size, which may not have enough power to detect an association of polymorphisms with small effects on depressive symptoms. The sample size is small because women in the postpartum period are not easily enrolled in research studies, due to the intensive time requirement of caring for their children. However, the present analyses may be considered as an exploratory study for understanding PPD susceptibility in a specific life period; the postpartum period is influenced most notably by hormones of the hypothalamus-pituitary-gonad axis.

\section{Acknowledgements}

We thank the CNPq for providing financial support.

\section{REFERENCES}

[1] American Psychiatric Association, "Diagnostic and Statistical Manual of Mental Disorders,” 4th Edition, American Psychiatric Association, Washington DC, 2000.

[2] H. A. Bennett, A. Einarson, A. Taddio, G. Koren and T. R. Einarson, "Prevalence of Depression during Pregnancy: Systematic Review," American College of Obstetricians and Gynecologists, Vol. 103, No. 4, 2004, pp. 698-709.

[3] A. Cantilino, C. F. Zambaldi, T. L. C. Albuquerque, J. A. Paes, A. C. P. Montenegro and E. B. Sougey, "Postpartum Depression in Recife-Brazil: Prevalence and Association with Bio-Socio-Demographic Factors," Journal of Brasileiro de Psiquiatria, Vol. 59, No. 1, 2010, pp. 1-9. doi:10.1590/S0047-20852010000100001

[4] P. Figueira, H. Corrêa, L. Malloy-Diniz and M. A. RomanoSilva, "Escala de Depressão Pós-Natal de Edimburgo Para Triagem No Sistema Público de Saúde,” Revista Saúde Pública, Vol. 43, No. 1, 2009, pp. 79-84. doi:10.1590/S0034-89102009000800012

[5] B. L. Parry, C. J. Meliska, D. L. Sorenson, A. M. Lopes, 
L. F. Martinez, S. Nowakowski, J. A. Elliott, R. L. Hauger and D. F. Kripke, "Plasma Melatonin Circadian Rhythm Disturbances during Pregnancy and Postpartum in Depressed Women and Women with Personal or Family Histories of Depression," American Journal of Psychiatry, Vol. 165, No. 12, 2008, pp. 1551-1558. doi:10.1176/appi.ajp.2008.08050709

[6] R. Xie, G. He, D. Koszycki, M. Walker and S. W. Wen, "Prenatal Social Support, Postnatal Social Support, and Postpartum Depression,” Annals of Epidemiology, Vol. 19, No. 4, 2009, pp. 637-643. doi:10.1016/j.annepidem.2009.03.008

[7] E. Frank, D. J. Kupfer, M. Jacob, S. J. Blumenthal and D. B. Jarrett, "Pregnancy-Related Affective Episodes among Women with Recurrent Depression,” American Journal of Psychiatry, Vol. 144, No. 3, 1987, pp. 288-293.

[8] J. L. Payne, D. F. MacKinnon, F. M. Mondimore, M. G. McInnis, B. Schweizer, R. B. Zamoiski, F. J. McMahon Jr., J. I. Nurnberger, J. P. Rice, W. Scheftner, W. Coryell, W. H. Berrettini, J. R. Kelsoe, W. Byerley, E. S. Gershon, J. R. DePaulo and J. B. Potash, "Familial Aggregation of Postpartum Mood Symptoms in Bipolar Disorder Pedigrees,” Bipolar Disord, Vol. 10, No. 1, 2008, pp. 38-44. doi:10.1111/j.1399-5618.2008.00455.X

[9] L. Forty, L. Jones, S. Macgregor, S. Caesar, C. Cooper, A Hough, L. Dean, S. Dave, A. Farmer, P. McGuffin, S. Brewster, N. Craddock and I. Jones, "Familiality of Postpartum Depression in Unipolar Disorder: Results of a Family Study," American Journal of Psychiatry, Vol. 163, No. 9, 2006, pp. 1549-1553. doi:10.1176/appi.ajp.163.9.1549

[10] H. Y. Meltzer and M. T. Lowy, "The Serotonin Hypothesis of Depression,” In: H. Y. Meltzer, Ed., Psychopharmacology: The Third Generation of Progress, Raven Press, 1987, pp. 513-526.

[11] G. E. Torres, R. R. Gainetdinov and M. G. Caron, "Plasma Membrane Monoamine Transporters: Structure, Regulation and Function,” Nature Reviews Neuroscience, Vol. 4, No. 1, 2003, pp. 13-25. doi:10.1038/nrn1008

[12] A. K. Koskela, S. Kaurijoki, K. H. Pietiläinen, L. Karhunen, U. Pesonen, J. T. Kuikka, J. Kaprio and A. Rissanen, "Serotonin Transporter Binding and Acquired Obesity: An Imaging Study of Monozygotic Twin Pairs," Physiology \& Behavior, Vol. 93, No. 4-5, 2008, pp. 724732. doi:10.1016/j.physbeh.2007.11.043

[13] K. P. Lesch, U. Balling, J. Gross, K. Strauss, B. L. Wolozin, D. L. Murphy and P. Riederer, "Organization of the Human Serotonin Transporter Gene,” Journal of Neural Transmission General Section, Vol. 95, No. 2, 1994, pp. 157-162. doi:10.1007/BF01276434

[14] K. P. Lesch, S. Jatzke, J. Meyer, G. Stober, O. Okladnova, R. Mossner and P. Riederer, "Mosaicism for a Serotonin Transporter Gene Promoter-Associated Deletion: Decreased Recombination in Depression,” Journal of Neural Transmission, Vol. 106, No. 11-12, 1999, pp. 1223-1230. doi:10.1007/s007020050236

[15] A. Caspi, K. Sugden, T. E. Moffitt, A. Taylor, I. W. Craig, H. Harrington, J. McClay, J. Mill, J. Martin, A. Braith- waite and R. Poulton, "Influence of Life Stress on Depression: Moderation by a Polymorphism in the 5-HTT Gene,” Science, Vol. 301, No. 5631, 2003, pp. 386-389. doi:10.1126/science.1083968

[16] K. Wilhelm, P. B. Mitchell, H. Niven, A. Finch, L. Wedgwood, A. Scimone, I. P. Blair, G. Parker and P. R. Schofield, "Life Events, First Depression Onset and the Serotonin Transporter Gene,” British Journal of Psychiatry, Vol. 188, No. 3, 2006, pp. 210-215. doi:10.1192/bjp.bp.105.009522

[17] G. Zalsman, Y. Y. Huang, M. A. Oquendo, A. K. Burke, X. Z. Hu, D. A. Brent, S. P. Ellis, D. Goldman and J. J. Mann, “Association of a Triallelic Serotonin Transporter Gene Promoter Region (5-HTTLPR) Polymorphism with Stressful Life Events and Severity of Depression," American Journal of Psychiatry, Vol. 163, No. 9, 2006, pp. 1588-1593. doi:10.1176/appi.ajp.163.9.1588

[18] N. Risch, R. Herrell, T. Lehner, K. Y. Liang, L. Eaves, J. Hoh, A. Griem, M. Kovacs, J. Ott and K. R. Merikangas, "Interaction between the Serotonin Transporter Gene (5-HTTLPR), Stressful Life Events, and Risk of Depression: A Meta-Analysis,” Journal of the American Medical Association, Vol. 301, No. 23, 2009, pp. 2462-2471. doi:10.1001/jama.2009.878

[19] D. A. Collier, M. J. Arranz, P. Sham, S. Battersby, H. Vallada, P. Gill, K. J. Aitchison, M. Sodhi, T. Li, G. W. Roberts, B. Smith, J. Morton, R. M. Murray, D. Smith and G. Kirov, "The Serotonin Transporter Is a Potential Susceptibility Factor for Bipolar Affective Disorder," Neuroreport, Vol. 7, No. 10, 1996, pp. 1675-1679. doi:10.1097/00001756-199607080-00030

[20] J. Sanjuan, R. Martin-Santos, L. Garcia-Esteve, J. M. Carot, R. Guillamat, A. Gutierrez-Zotes, I. Gornemann, F. Canellas, E. Baca-Garcia, M. Jover, R. Navines, V. Valles, E. Vilella, Y. de Diego, J. A. Castro, J. L. Ivorra, E. Gelabert, M. Guitart, A. Labad, F. Mayoral, M. Roca, M. Gratacos, J. Costas, J. van Os and R. de Frutos, "Mood Changes after Delivery: Role of the Serotonin Transporter Gene,” British Journal of Psychiatry, Vol. 193, No. 5, 2008, pp. 383-388. doi:10.1192/bjp.bp.107.045427

[21] B. Doornbos, J. Dijck-Brouwer, I. P. Kema, M. A. C. Tanke, S. A. van Goor, F. A. Muskiet and J. Korf, “The Development of Peripartum Depressive Symptoms Is Associated with Gene Polymorphisms of MAOA, 5-HTT and COMT," Progress in Neuro-Psychopharmacology and Biological Psychiatry, Vol. 33, No. 5, 2009, pp. 1250-1254. doi:10.1016/j.pnpbp.2009.07.013

[22] S. E. Taylor, B. M. Way, W. T. Welch, C. J. Hilmert, B. J. Lehman and N. I. Eisenberger, "Early Family Environment, Current Adversity, the Serotonin Transporter Promoter Polymorphism, and Depressive Symptomatology," Biological Psychiatry, Vol. 60, No. 7, 2006, pp. 671-676. doi:10.1016/j.biopsych.2006.04.019

[23] J. C. Pascual, J. Soler, M. Baiget, A. Cortés, A. Menoyo, J. Barrachina, M. Ropero, M. Gomà, E. Álvarez and V. Pérez, “Asociación Entre el Gen del Transportador de la Serotonina y Rasgos de Personalidad en Pacientes con Trastorno Límite de la Personalidad Evaluados Mediante el Zuckerman-Kuhlman Personality Questionnaire (ZKPQ)," 
Actas Esp Psiquiatr, Vol. 35, No. 6, 2007, pp. 382-386.

[24] F. C. Parra, R. C. Amado, J. R. Lambertucci, J. Rocha, C. M. Antunes and S. D. Pena, "Color and Genomic Ancestry in Brazilians," Proceedings of the National Academy of Sciences of the United States of America, Vol. 200, 2003, pp. 177-1782. doi:10.1073/pnas.0126614100

[25] C. Gzorenstein and L. Andrade, "Validation of a Portuguese Version of the Beck Depression Inventory and the State-Trait Anxiety Inventory in Brazilian Subjects," Brazilian Journal of Medical and Biological Research, Vol. 29, No. 4, 1996, pp. 453-457.

[26] D. K. Lahiri and J. I. Nurnberger Jr., “A Rapid Non-Enzymatic Method for the Preparation of HMW DNA from Blood for RFLP Studies," Nucleic Acids Research, Vol. 19, No. 19, 1991, p. 5444. doi:10.1093/nar/19.19.5444

[27] R. Kohen, K. C. Cain, P. H. Mitchell, K. J. Becker, A. Buzaitis, S. P. Millard, G. P. Navaja, L. Teri, D. Tirschwell and R. Veith, "Association of Serotonin Transporter Gene Polymorphisms with Post-Stroke Depression,” Archives of General Psychiatry, Vol. 65, No. 11, 2008, pp. 1296-1302. doi:10.1001/archpsyc.65.11.1296

[28] J. Long, R. Williams and M. Urbanek, “An E-M Algorithm and Testing Strategy for Multiple-Locus Haplotypes," American Journal of Human Genetics, Vol. 56, No. 3, 1995, pp. 799-810.

[29] R. Peterson, D. Goldman and J. Long, "Nucleotide Sequence Diversity in Non-Coding Regions of ALDH2 as Revealed by Restriction Enzyme and SSCP Analysis,” Human Genetics, Vol. 104, No. 2, 1999, pp. 177-187. doi:10.1007/s004390050932

[30] L. Excoffier, G. Laval and S. Schneider, “Arlequin (Version 3.0): An Integratedsoftware Package for Population Genetics Data Analysis,” Evolutionary Bioinformatics Online, Vol. 1, No. 1, 2005, pp. 47-50.

[31] Y. Benjamini and Y. Hochberg, "Controlling the False Discovery Rate: A Practical and Powerful Approach to Multiple Testing,” Journal of the Royal Statistical Society, Vol. 57, No. 1, 1995, pp. 289-300.

[32] A. Heils, A. Teufel, S. Petri, G. Stober, P. Riederer, D. Bengel and K. P. Lesch, "Allelic Variation of Human Serotonin Transporter Gene Expression,” Journal of Neurochemistry, Vol. 66, No. 6, 1996, pp. 2621-2624. doi:10.1046/j.1471-4159.1996.66062621.x

[33] L. Pezawas, A. Meyer-Lindenberg, E. M. Drabant, B. A. Verchinski, K. E. Munoz, B. S. Kolachana, M. F. Egan, V. S. Mattay, A. R. Hariri and D. R. Weinberger, "5HTTLPR Polymorphism Impacts Human CingulateAmygdala Interactions: A Genetic Susceptibility Mechanism for Depression,” Nature Neuroscience, Vol. 8, No. 6, 2005, pp. 828-834. doi:10.1038/nn1463

[34] K. P. Lesch, D. Bengel, A. Heils, S. Z. Sabol, B. D. Greenberg, S. Petri, J. Benjamin, C. R. Muller, D. H. Hamer and D. L. Murphy, "Association of Anxiety-Related Traits with a Polymorphism in the Serotonin Transporter Gene Regulatory Region,” Science, Vol. 274, No. 5292, 1996, pp. 1527-1531. doi:10.1126/science.274.5292.1527

[35] V. M. Chorbov, E. A. Lobos, A. A. Todorov, A. C. Heath, K. N. Botteron and R. D. Todd, "Relationship of 5HTTLPR Genotypes and Depression Risk in the Presence of Trauma in a Female Twin Sample,” American Journal of Medical Genetics Part B: Neuropsychiatric Genetics, Vol. 144B, No. 6, 2007, pp. 830-833. doi:10.1002/ajmg.b.30534

[36] M. Laucht, J. Treutlein, D. Blomeyer, A. F. Buchmann, B. Schmid, K. Becker, U. S. Zimmermann, M. H. Schmidt, G. Esser, M. Rietschel and T. Banaschewski, "Interaction between the 5-HTTLPR Serotonin Transporter Polymorphism and Environmental Adversity for Mood and Anxiety Psychopathology: Evidence from a High-Risk Community Sample of Young Adults,” International Journal of Neuropsychopharmacology, Vol. 12, No. 6, 2009, pp. 737-747. doi:10.1017/S1461145708009875

[37] P. G. Surtees, N. W. Wainwright, S. A. Willis-Owen, R. Luben, N. E. Day and J. Flint, "Social Adversity, the Serotonin Transporter (5-HTTLPR) Polymorphism and Major Depressive Disorder,” Biological Psychiatry, Vol. 59, No. 3, 2006, pp. 224-229. doi:10.1016/j.biopsych.2005.07.014

[38] J. Segal, L. C. Schenkel, M. H. Oliveira, G. A. Salum, C. H. Bau, G. G. Manfro and S. Leistner-Segal, "Novel Allelic Variants in the Human Serotonin Transporter Gene Linked Polymorphism (5-HTTLPR) among Depressed Patients with Suicide Attempt," Neuroscience Letters, Vol. 451, No. 1, 2009, pp. 79-82. doi:10.1016/j.neulet.2008.12.015

[39] S. Veletza, M. Samakouri, G. Emmanouil, G. Trypsianis, N. Kourmouli and M. Livaditis, "Psychological Vulnerability Differences in Students-Carriers or Not of the Serotonin Transporter Promoter Allele S: Effect of Adverse Experiences,” Synapse, Vol. 63, No. 3, 2009, pp. 193200. doi:10.1002/syn.20598

[40] M. Alaerts, S. Ceulemans, D. Forero, L. N. Moens, S. De Zutter, L. Heyrman, A. S. Lenaerts, K. F. Norrback, D. Goossens, P. De Rijk, L. G. Nilsson, R. Adolfsson and J. Del-Favero, "Detailed Analysis of the Serotonin Transporter Gene (SLC6A4) Shows No Association with Bipolar Disorder in the Northern Swedish Population," American Journal of Medical Genetics Part B: Neuropsychiatric Genetics, Vol. 150B, 2008, pp. 585-592. doi:10.1002/ajmg.b.30853

[41] F. Assal, M. Alarcón, E. C. Solomon, D. Masterman, D. H. Geschwind and J. L. Cummings, "Association of the Serotonin Transporter and Receptor Gene Polymorphisms in Neuropsychiatric Symptoms in Alzheimer Disease," Archives of Neurology, Vol. 61, 2004, pp. 1249-1253. doi:10.1001/archneur.61.8.1249

[42] H. B. Kumar, M. Purushottam, S. Kubendran, P. Gayathri, O. Mukherjee, A. R. Murthy, S. Ghosh, P. Chandra, Y. C. Reddy, V. Benegal, S. K. Brahmachari and S. Jain, "Serotonergic Candidate Genes and Puerperal Psychosis: An Association Study,” Psychiatric Genetics, Vol. 17, No. 2, 2007, pp. 53-260. 